\title{
ESTIMATIVA DE LINHAS DE RECURSOS E PROGRAMAS PARA IMPLANTAÇÃO DE POLÍTICAS FLORESTAIS NA REGIÃO SUDESTE DO PARÁ
}

\author{
Fabiano dos Santos Rodrigues ${ }^{1}$; Fernando Michelotti ${ }^{2}$ \\ ${ }^{1}$ Discente do curso de Ciências Sociais, Faculdade de Ciências Agrárias de Marabá (FCAM), Universidade Federal do \\ Pará (UFPA), Marabá, Pará. Bolsista PROINT. E-mail: rodriguesaps @ yahoo.com.br. \\ ${ }^{2}$ Prof., M.Sc., FCAM, UFPA, E-mail: fmichelotti@ufpa.br.
}

RESUMO: A região Sudeste do Pará vem absorvendo uma série de transformações econômicas, políticas e sociais. Mudanças que tiveram grandes incentivos do governo brasileiro, como incentivos fiscais, concessão de grandes áreas para o desenvolvimento da pecuária e de outras práticas agrícolas de grande porte, dentre outros. Estes incentivos privilegiaram grandes grupos econômicos, grandes projetos. Os grandes projetos deram prioridades a elementos externos da região não incluindo parte das populações já existentes aqui e as classes subalternas. Essas grandes transformações atraíram para região um número considerável de novos habitantes, que se aglomerou em cidades que já existiam e em outras que passaram a existir. Em 1980 eram apenas cinco municípios na região e em 1996 já eram vinte e nove. Isso é apenas uma dimensão do que foram essas transformações. No cenário agrário, na década de oitenta, a cidade de Marabá foi o maior ponto de conflitos agrários do Brasil refletindo assim a opção do Estado brasileiro, em privilegiar ações de acumulação de capitais e de descaso às populações mais pobres. Como consequiência dessas opções, boa parte da vegetação na região foi destruída pra dar lugar a alguns destes empreendimentos, principalmente os agropecuários. Apesar desse histórico de ocupação inicial e de suas consequiências, na atualidade há uma maior preocupação com a sustentabilidade do modelo de desenvolvimento. Inúmeras iniciativas de ampliação da sustentabilidade agropecuária, na região, têm sido fomentadas por órgãos governamentais e instituições civis. O presente trabalho tem por objetivo fazer um levantamento dos aportes técnicos, políticos, econômicos e institucionais, que possibilitem a implantação de sistemas agrofloerestais (SAF's) como prática agrícola na região Sul e Sudeste do Pará. Trata-se de um estudo quantitativo e qualitativo destes recursos, que são desde linhas de crédito, assistência técnica e extensão rural, programas governamentais, dentre outros que possam colaborar com a difusão e a implementação desta prática na agricultura familiar local. Além disso, busca fortalecer o paradigma agroecológico como necessário e fundamental para a construção científica local. O levantamento está sendo desenvolvido através de revisão literária, entrevistas, visitas a órgãos públicos, a entidades de classe, e sítios eletrônicos. Mais especificamente estão sendo estudados dois grandes projetos que prometem garantir essa sustentabilidade, para atividades econômicas que há na região o: i) - "Distrito Florestal de Carajás", que cultiva em áreas dos Estados do Tocantins, Pará e Maranhão o que o setor guseiro denomina de florestas energéticas e conta com um aporte de recursos financeiros e políticos muito organizado. Este projeto não tem como objetivo garantir a diversidade natural, porém, o estudo pode apontar possíveis impactos no cenário regional; ii) - "Programa Um Bilhão de Árvores Para Amazônia", do Governo do Estado do Pará, que como o nome sugere pretende plantar no Estado do Pará um bilhão de árvores até o ano de 2013. Espera-se Levantar ações, tanto governamentais como da iniciativa privada, relacionadas à implantação de sistemas agroflorestais na região Sudeste do Pará colaborando para a elaboração de políticas públicas mais adequadas ao funcionamento do ambiente institucional, sócio-cultural e econômico relacionado à produção, comercialização e inovação agroflorestal.

PALAVRAS - CHAVE: Sustentabilidade, sudeste do Pará, sistemas agroflorestais, políticas públicas. 